\title{
Valsartan metal complexes as capture and reversible storage media for methane
}

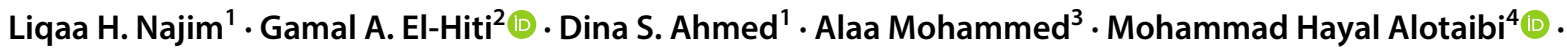 \\ Emad Yousif ${ }^{3}$ (1)
}

Received: 11 May 2020 / Accepted: 29 May 2020 / Published online: 6 June 2020

(c) The Author(s) 2020

\begin{abstract}
Three valsartan metal (tin, nickel, and magnesium) complexes were examined as capture and storage media for methane under high temperature $(323 \mathrm{~K})$ and pressure $(50 \mathrm{bar})$ conditions. The surface morphology of the complexes were examined using Field emission scanning electron microscopy and displayed porous structures comprising particles of different shapes and sizes. The narrow pore-size distribution of metal complexes makes them suitable materials for methane capture. The methane adsorption-desorption isotherms of the metal complexes were reversible. The tin(IV) and nickel(II) complexes exhibited type-III physisorption isotherms, while the magnesium(II) complex displayed a type-IV physisorption isotherm. Both types of isotherms are typical for mesoporous materials. The magnesium(II) complex was more efficient compared with the tin(IV) and nickel(II) complexes. It exhibited a remarkable methane uptake capacity of $71.68 \mathrm{~cm}^{3} / \mathrm{g}$ under optimized conditions.
\end{abstract}

Keywords Methane $\cdot$ Storage media $\cdot$ Adsorption capacity $\cdot$ Valsartan metal complexes $\cdot$ Methane $\cdot$ Adsorption-desorption isotherms

\section{Introduction}

Natural gas is an alternative energy source to petroleum and coal. Commercial natural gas contains methane $\left(\mathrm{CH}_{4}\right.$; 95\%), ethane (3.2\%), and other gas impurities (1.7\%) [1]. Gas impurities have a negative effect on the $\mathrm{CH}_{4}$ storage capacities of adsorbent materials. Compared to petroleum,

Gamal A. El-Hiti

gelhiti@ksu.edu.sa

$\triangle$ Mohammad Hayal Alotaibi

mhhalotaibi@kacst.edu.sa

$\triangle$ Emad Yousif

emadayousif@gmail.com

1 Department of Medical Instrumentation Engineering, AlMansour University College, Baghdad, Iraq

2 Cornea Research Chair, Department of Optometry, College of Applied Medical Sciences, King Saud University, P.O. Box 10219, Riyadh 11433, Saudi Arabia

3 Department of Chemistry, College of Science, Al-Nahrain University, Baghdad 64021, Iraq

4 National Center for Petrochemicals Technology, King Abdulaziz City for Science and Technology, P.O. Box 6086, Riyadh 11442, Saudi Arabia the combustion of natural gas produces intense heat and light energy, as well as low carbon emissions [2-4]. Two techniques are commonly utilized to measure the quantity of $\mathrm{CH}_{4}$ adsorbed onto porous materials [5]. The first technique involves the measurement of weight changes in the adsorbent at various $\mathrm{CH}_{4}$ pressures by gravimetry [5]. The second technique involves employing a volumetric method to record the changes in the volume of adsorbed $\mathrm{CH}_{4}$ in porous materials under standard conditions [5]. The experiments conducted at high pressures are more complicated and generate errors compared to those performed at low pressures $[6,7]$. The experimental errors can be effectively reduced by measuring the background $\mathrm{CH}_{4}$ adsorption isotherms and subtracting the values from the actual experimental readings [8]. In addition, pure $\mathrm{CH}_{4}$ should be used, since trace amounts of water and hydrocarbons can induce a large error in the adsorption measurements [8]. $\mathrm{CH}_{4}$ capture is a slow process, because $\mathrm{CH}_{4}$ is non-polar and its interaction with adsorbents is weak [9].

$\mathrm{CH}_{4}$ is responsible for approximately $30 \%$ of global warming and climate change [9]. Consequently, various porous materials have been designed and tested as capture media for $\mathrm{CH}_{4}$ [10-13]. The most common materials used for the adsorption of $\mathrm{CH}_{4}$ are graphite, zeolites, 
silica, metal-organic frameworks (MOFs), porous-organic polymers, polyphosphates, and activated carbons [14-16]. However, limited success has been achieved thus far. MOFs are potential effective materials for gas capture, and their pores can be tuned to improve their adsorption capacities [14]. In addition, the functional groups within MOFs control their gas-uptake capacity [15]. The adsorption and capture of gases over using new materials as storage media have received attention [17-21].

Recently, we reported the synthesis of various materials and their efficient applications as storage media for carbon dioxide [22-26] as a continuation of our general interest in designing and new materials for various applications [27-31]. For example, valsartan metal complexes were found to be very effective as carbon dioxide $\left(\mathrm{CO}_{2}\right)$ storage media [26]. Therefore, it is of interest to determine if these materials can be used to store $\mathrm{CH}_{4}$. Valsartan is a stable, safe, and non-toxic medication that contains heterocyclic and aryl moieties [32,33].

\section{Materials and methods}

Valsartan metal complexes 1-3 (Fig. 1) were synthesized, as previously reported, via the reaction of valsartan and metal chlorides in a 2:1 molar ratio [26]. Field emission scanning electron microscopy (FESEM) was conducted using a TESCAN MIRA3 LMU system. The $\mathrm{CH}_{4}$ uptake was measured on an H-sorb 2600 high-pressure volumetric adsorption analyzer. The samples of complexes 1-3 $(1.0 \mathrm{~g})$ were degassed for $1 \mathrm{~h}$ at $50^{\circ} \mathrm{C}$ in a vacuum oven to completely remove any trace of moisture or solvent trapped within the pores. Each $\mathrm{CH}_{4}$ uptake experiment was repeated several times for pressure optimization.

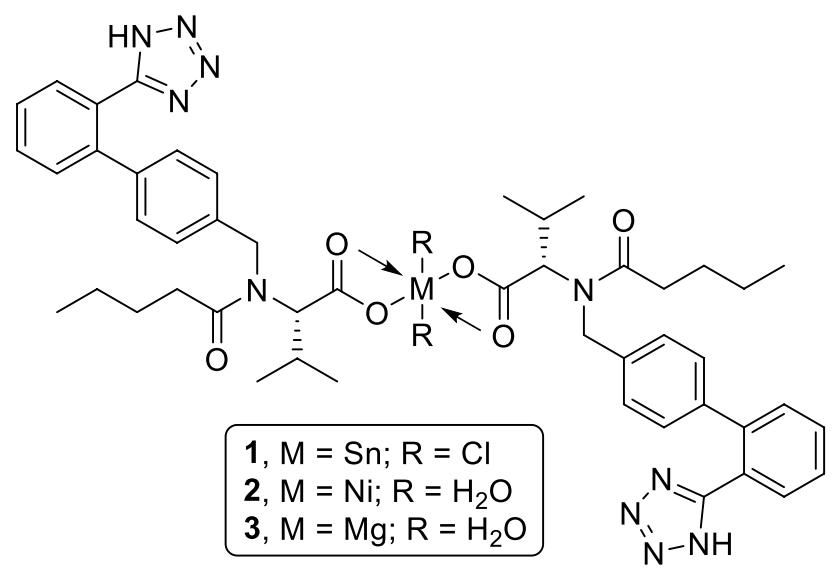

Fig. 1 Valsartan metal complexes 1-3

\section{Results and discussion}

The surface morphologies of complexes 1-3 (Fig. 1) were examined by FESEM. The FESEM images of 1-3 (Fig. 2) show porous structures that are homogeneous and rough with irregular surfaces composed of loose agglomerates of tiny particles. In addition, the particles are of different shapes and contain crystals, and a number of cracks. The porosity of complexes was analyzed in terms of particles size. The pore volumes and diameters of complexes 1-3 were in the range of $0.011-0.108 \mathrm{~cm}^{3} / \mathrm{g}$ and $6.50-12.47 \mathrm{~nm}$, respectively, and their surface areas were small (16.6, 22.8, and $16.0 \mathrm{~m}^{2} / \mathrm{g}$, respectively) [26]. The narrow pore-size distribution of complexes 1-3 makes them suitable materials for $\mathrm{CH}_{4}$ capture.

The $\mathrm{CH}_{4}$ adsorption-desorption isotherms of complexes 1-3, recorded at $323 \mathrm{~K}$ and 50 bar, are shown in Figs. 3, 4 and 5. The selected temperature and pressure were based on the profermace of these complexes as storage media for $\mathrm{CO}_{2}$ [26]. There was no overlap between the adsorption-desorption isotherms of $\mathbf{1}$ and $\mathbf{2}$. However, the branches for the adsorption and desorption of $\mathbf{3}$ overlapped completely. Complexes $\mathbf{1}$ and $\mathbf{2}$ showed type-III physisorption isotherms (Figs. 3 and 4, respectively), while complex 3 exhibited a type-IV physisorption isotherm (Fig. 5). Both types of isotherms are typical for mesoporous materials, in which multilayers are not formed. The isotherms showed that the interaction between $\mathrm{CH}_{4}$ and the complexes (1-3) was relatively weak, and the gas mostly adsorbed at the active site of each complex [34, 35]. It was evident that the $\mathrm{CH}_{4}$ adsorption-desorption isotherms are roughly reversible.

The $\mathrm{CH}_{4}$ uptake capacities of complexes 1-3 increased sharply with increase in pressure and were found maximum at 50 bar. Saturation was not achieved in the experiments attempted, which clearly indicated that a high adsorption capacity can be achieved at high pressures. The $\mathrm{Mg}(\mathrm{II})$ complex (3) was the most favorable, desirable, and practical medium for $\mathrm{CH}_{4}$ capture. This complex could adsorb $\mathrm{CH}_{4}$ even with exposure to the atmosphere and could release the gas from its cavities on releasing pressure. The $\mathrm{CH}_{4}$ uptake capacities of complexes 1-3 at $323 \mathrm{~K}$ and 50 bar are presented in Table 1.

Complex 3 showed the highest $\mathrm{CH}_{4}$ adsorption capacity $\left(71.68 \mathrm{~cm}^{3} / \mathrm{g} ; 5.15 \mathrm{wt} \%\right)$ compared to complexes 1 and $2\left(10.47\right.$ and $3.76 \mathrm{~cm}^{3} / \mathrm{g}$, respectively). In contrast, $\mathrm{CO}_{2}$ adsorption of 1-3 under similar condition was mainly dependent on their surface area and the interaction with the gas [26]. Complex 2 which has the highest surface area $\left(S_{\mathrm{BET}}=22.75 \mathrm{~m}^{2} / \mathrm{g}\right)$ was the most effective medium for $\mathrm{CO}_{2}$ storage (6.8 wt \%) compared to complexes $1\left(16.63 \mathrm{~m}^{2} / \mathrm{g} ; 5.4 \mathrm{wt} \%\right)$, and $2\left(15.96 \mathrm{~m}^{2} / \mathrm{g} ; 4.8 \mathrm{wt} \%\right)$ 



Fig. 2 FESEM images of complexes $\mathbf{1}(\mathbf{a} 2 \mu \mathrm{m}$ and $\mathbf{b} 500 \mathrm{~nm}), \mathbf{2}(\mathbf{c} 2 \mu \mathrm{m}$ and $\mathbf{d} 500 \mathrm{~nm})$, and $\mathbf{3}(\mathbf{e} 2 \mu \mathrm{m}$ and $\mathbf{f} 200 \mathrm{~nm})$ 


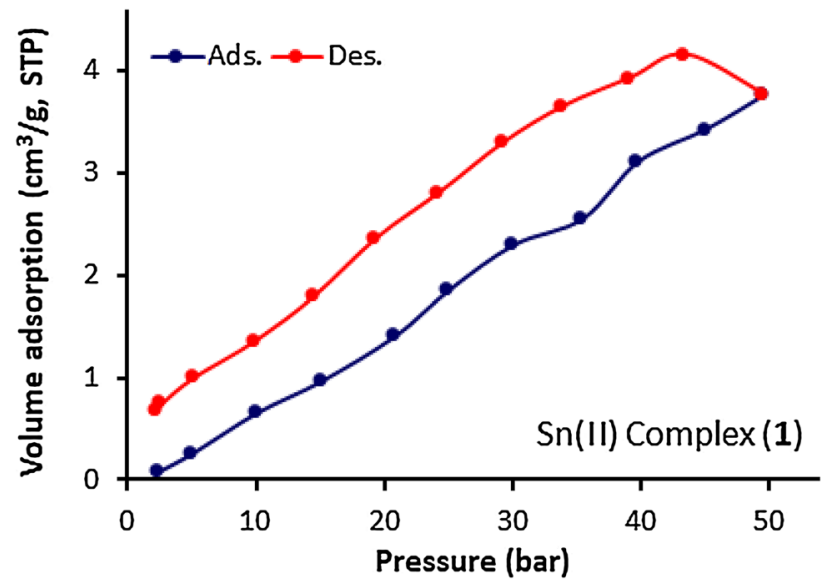

Fig. $3 \mathrm{CH}_{4}$ adsorption-desorption isotherms of $\mathbf{1}$

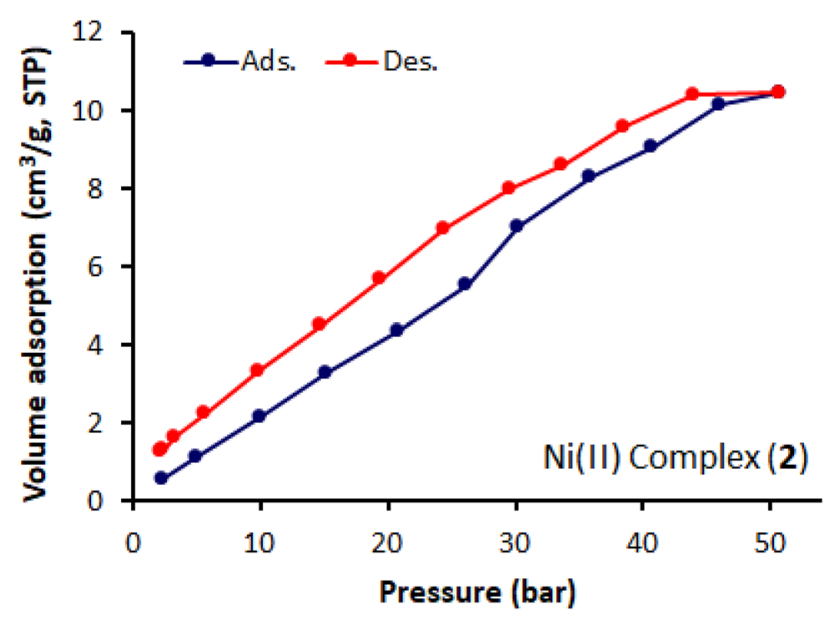

Fig. $4 \mathrm{CH}_{4}$ adsorption-desorption isotherms of 2

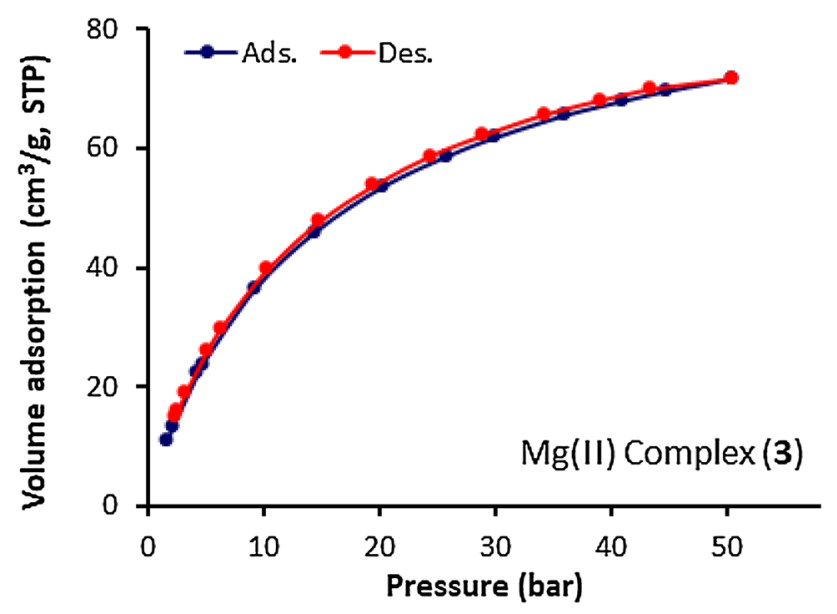

Fig. $5 \mathrm{CH}_{4}$ adsorption-desorption isotherms of $\mathbf{3}$
Table 1 Methane uptake capacities of complexes 1-3 at $323 \mathrm{~K}$ and 50 bar

\begin{tabular}{lccc}
\hline Complex & \multicolumn{3}{c}{$\mathrm{CH}_{4}$ uptake capacity } \\
\cline { 2 - 4 } & $\mathrm{cm}^{3} / \mathrm{g}$ & $\mathrm{mmol} / \mathrm{g}$ & $\mathrm{wt} \%$ \\
\hline Sn(IV) complex $\mathbf{1}$ & 3.76 & 0.16 & 0.26 \\
Ni(II) complex 2 & 10.47 & 0.46 & 0.74 \\
Mg(II) complex $\mathbf{3}$ & 71.68 & 3.19 & 5.15 \\
\hline
\end{tabular}

[26]. The variation in the $\mathrm{CH}_{4}$ capture capacities of 1-3 depends mainly on the strength of the interaction between the gas and adsorbent materials. Regardless of the pressure (either low or high), the capture of $\mathrm{CH}_{4}$ occurs more effectively in particles with tuned pore sizes and volumes. It has been reported that the modification of MOF pores, though incorporation with magnesium-decorated fullerenes, can increase the gas-adsorption capacity significantly [36]. This process results in tuned pores and increases the enthalpy of adsorption. Carboxylic acid and heterocycles are the most common units utilized in the construction of MOFs [37]. These units are hydrophobic enough to enhance the $\mathrm{CH}_{4}$ uptake of and interaction with the MOFs, as well as increase the moisture stability of the framework [37, 38].

In addition to the surface area, the tuned pore volume and size play significant roles in controlling the gas-adsorption capacity of adsorbent materials. In the current work, the $\mathrm{Ni}$ (II) complex has a larger surface area than the magnesium complex; however, it is less efficient as a storage medium for $\mathrm{CH}_{4}$. The enthalpy of adsorption can be increased through the incorporation of coordinatively unsaturated metal sites within the MOFs [39]. In addition, the doping of MOFs with a transition metal or alkali can improve their gas-adsorption capacities [40]; however, only few examples have been successful for $\mathrm{CH}_{4}$ capture [41].

\section{Conclusions}

Three valsartan metal complexes were investigated as potential capture and storage media for $\mathrm{CH}_{4}$. The complexes exhibited different adsorption-desorption isotherms depending on the type of metal. The magnesium complex was more effective than the other two as a storage medium for $\mathrm{CH}_{4}$. A remarkable $\mathrm{CH}_{4}$ uptake capacity $\left(71.68 \mathrm{~cm}^{3} / \mathrm{g}\right)$ was achieved using the magnesium-valsartan complex.

Acknowledgements The authors are grateful to the Deanship of Scientific Research, King Saud University for funding through Vice Deanship of Scientific Research Chairs. We thank Al-Nahrain University for the technical support. 
Open Access This article is licensed under a Creative Commons Attribution 4.0 International License, which permits use, sharing, adaptation, distribution and reproduction in any medium or format, as long as you give appropriate credit to the original author(s) and the source, provide a link to the Creative Commons licence, and indicate if changes were made. The images or other third party material in this article are included in the article's Creative Commons licence, unless indicated otherwise in a credit line to the material. If material is not included in the article's Creative Commons licence and your intended use is not permitted by statutory regulation or exceeds the permitted use, you will need to obtain permission directly from the copyright holder. To view a copy of this licence, visit http://creativecommons.org/licenses/by/4.0/.

\section{References}

1. Liss WE, Thrasher WH, Steinmetz GF, Chowdiah P, Attari A (1992) Variability of natural gas composition in select major Metropolitan areas of the United States. Gas Technology Institute, GRI92/0123

2. Armor JN (2013) Emerging importance of shale gas to both the energy and chemicals landscape. J Energy Chem 22:21-26. https://doi.org/10.1016/S2095-4956(13)60002-9

3. Alvarez RA, Pacala SW, Winebrake JJ, Chameides WL, Hamburg SP (2012) Greater focus needed on methane leakage from natural gas infrastructure. Proc Natl Acad Sci USA 109:64356440. https://doi.org/10.1073/pnas.1202407109

4. Howarth RW, Santoro R, Ingraffea A (2011) Methane and the greenhouse-gas footprint of natural gas from shale formations. Clim Change 106:679-690. https://doi.org/10.1007/s1058 4-011-0061-5

5. Peng Y, Srinivas G, Wilmer CE, Eryazici I, Snurr RQ, Hupp JT, Yildirim T, Farha OK (2013) Simultaneously high gravimetric and volumetric methane uptake characteristics of the metalorganic framework NU-111. Chem Commun 49:2992-2994. https://doi.org/10.1039/C3CC40819A

6. Peng Y, Krungleviciute V, Eryazici I, Hupp JT, Farha OK, Yildirim T (2013) Methane storage in metal-organic frameworks: current records, surprise findings, and challenges. J Am Chem Soc 135:11887-11894. https://doi.org/10.1021/ja4045289

7. Zhou W, Wu H, Hartman MR, Yildirim T (2007) Hydrogen and methane adsorption in metal-organic frameworks: a highpressure volumetric study. J Phys Chem C 111:16131-16137. https://doi.org/10.1021/jp074889i

8. Mason JA, Veenstra M, Long JR (2014) Evaluating metalorganic frameworks for natural gas storage. Chem Sci 5:32-51. https://doi.org/10.1039/C3SC52633J

9. Kim J, Maiti A, Lin LC, Stolaroff JK, Smit B, Aines RD (2013) New materials for methane capture from dilute and mediumconcentration sources. Nat Commun 4:1694. https://doi. org/10.1038/ncomms2697

10. Kumar KV, Preuss K, Titirici M-A, Rodríguez-Reinoso F (2017) Nanoporous materials for the onboard storage of natural gas. Chem Rev 117:1796-1825. https://doi.org/10.1021/acs.chemr ev.6b00505

11. Makal TA, Li J-R, Lu W, Zhou H-G (2012) Methane storage in advanced porous materials. Chem Soc Rev 41:7761-7779. https ://doi.org/10.1039/c2cs35251f

12. Bracco S, Piga D, Bassanetti I, Perego J, Comotti A, Sozzani P (2017) Porous 3D polymers for high pressure methane storage and carbon dioxide capture. J Mater Chem A 5:10328-10337. https://doi.org/10.1039/c7ta00934h

13. Tong M, Lan Y, Yang Q, Zhong C (2018) High-throughput computational screening and design of nanoporous materials for methane storage and carbon dioxide capture. Green Energy Environ 3:107-119. https://doi.org/10.1016/j.gee.2017.09.004

14. Konstas K, Osl T, Yang Y, Batten M, Burke N, Hill AJ, Hill MR (2012) Methane storage in metal organic frameworks. J Mater Chem 22:16698. https://doi.org/10.1039/C2JM32719H

15. Li B, Wen H-M, Zhou W, Xu JQ, Chen B (2016) Porous metalorganic frameworks: promising materials for methane storage. Chem 1:557-580. https://doi.org/10.1016/j.chempr.2016.09.009

16. Feng G, Geng J, Feng F, Huang W (2020) Solvent-controlled self-assembly of tetrapodal [4 +4$]$ phosphate organic molecular cage. Sci Rep 10:4712. https://doi.org/10.1038/s41598-02061813-6

17. Wang K, Yan X, Komarneni S (2018) CO2 Adsorption by several types of pillared Montmorillonite clays. Appl Petrochem Res 8:173-177. https://doi.org/10.1007/s13203-018-0206-9

18. Zare A, Khanipour M, Sarverstani HK, Kakavandi IA, Shokroo EJ, Farniaei M, Baghbani M (2019) Hydrogen and carbon dioxide recovery from the petrochemical flare gas to methanol production using adsorption and absorption combined high-efficient method. Appl Petrochem Res 9:127-145. https://doi.org/10.1007/s1320 3-019-0232-2

19. Wilson MH, Mohler DT, Groppo JG, Grubbs T, Kesner S, Frazar EM, Shea A, Crofcheck C, Crocke M (2016) Capture and recycle of industrial $\mathrm{CO} 2$ emissions using microalgae. Appl Petrochem Res 6:279-293. https://doi.org/10.1007/s13203-016-0162-1

20. Takht Ravanchi M, Sahebdelfar S (2014) Carbon dioxide capture and utilization in petrochemical industry: potentials and challenges. Appl Petrochem Res 4:63-77. https://doi.org/10.1007/ s13203-014-0050-5

21. Vijayaraghavan R (2013) Noble metal ion-substituted ceria as efficient oxygen storage catalysts for clean combustion of fuels. Appl Petrochem Res 3:79-82. https://doi.org/10.1007/s1320 3-013-0032-z

22. Omer RM, Al-Tikrity ETB, El-Hiti GA, Alotibi MF, Ahmed DS, Yousif E (2020) Porous aromatic melamine Schiff bases as highly efficient media for carbon dioxide storage. Processes 8:7. https:// doi.org/10.3390/pr8010017

23. Satar HA, Ahmed AA, Yousif E, Ahmed DS, Alotibi MF, El-Hiti GA (2019) Synthesis of novel heteroatom-doped porous-organic polymers as environmentally efficient media for carbon dioxide storage. Appl Sci 9:4314. https://doi.org/10.3390/app9204314

24. Ahmed DS, El-Hiti GA, Yousif E, Hameed AS, Abdalla M (2017) New eco-friendly phosphorus organic polymers as gas storage media. Polymers 9:336. https://doi.org/10.3390/polym9080336

25. Hadi AG, Jawad K, Yousif E, El-Hiti GA, Alotaibi MH, Ahmed DS (2019) Synthesis of telmisartan organotin(IV) complexes and their use as carbon dioxide capture media. Molecules 24:1631. https://doi.org/10.3390/molecules24081631

26. Mohammed A, Yousif E, El-Hiti GA (2020) Synthesis and use of valsartan metal complexes as media for carbon dioxide storage. Materials 13:1183. https://doi.org/10.3390/ma13051183

27. El-Hiti GA, Ahmed DS, Yousif E, Alotaibi MH, Star HA, Ahmed AA (2020) Influence of polyphosphates on the physicochemical properties of poly(vinyl chloride) after irradiation with ultraviolet light. Polymers 12:193. https://doi.org/10.3390/polym12010193

28. Ahmed AA, Ahmed DS, El-Hiti GA, Alotaibi MH, Hashim H, Yousif E (2019) SEM morphological analysis of irradiated polystyrene film doped by a Schiff base containing a 1,2,4-triazole ring system. Appl Petrochem Res 9:169-177. https://doi.org/10.1007/ s13203-019-00235-6

29. Hadi AG, Jawad K, El-Hiti GA, Alotaibi MH, Ahmed AA, Ahmed DS, Yousif E (2019) Photostabilization of poly(vinyl chloride) by organotin (IV) compounds against photodegradation. Molecules 24:3557. https://doi.org/10.3390/molecules24193557

30. Yousif E, Ahmed DS, El-Hiti GA, Alotaibi MH, Hashim H, Hameed AS, Ahmed A (2018) Fabrication of novel ball-like

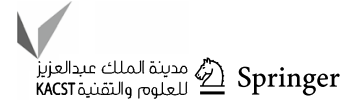


polystyrene films containing Schiff bases microspheres as photostabilizers. Polymers 10:1185. https://doi.org/10.3390/polym 10111185

31. Yousif E, Hasan A, El-Hiti GA (2016) Spectroscopic, physical and topography of photochemical process of PVC films in the presence of Schiff base metal complexes. Polymers 8:204. https ://doi.org/10.3390/polym8060204

32. Corea L, Cardoni O, Fogari R, Innocenti P, Porcellati C, Provvidenza M, Meilenbrock S, Sullivan J, Bodin F (1996) Valsartan, a new angiotensin II antagonist for the treatment of essential hypertension: a comparative study of the efficacy and safety against amlodipine. Clin Pharmacol Ther 60:341-346. https://doi. org/10.1016/S0009-9236(96)90061-2

33. Abraham I, MacDonald K, Hermans C, Aerts A, Lee C, Brié H, Vancayzeele S (2011) Real-world effectiveness of valsartan on hypertension and total cardiovascular risk: review and implications of a translational research program. Vasc Health Risk Manag 7:209-235. https://doi.org/10.2147/VHRM.S9434

34. Thommes M, Kaneko K, Neimark AV, Olivier JP, RodriguezReinoso F, Rouquerol J, Sing KSW (2015) Physisorption of gases, with special reference to the evaluation of surface area and pore size distribution (IUPAC Technical Report). Pure Appl Chem 87:1051-1069. https://doi.org/10.1515/pac-2014-1117

35. Cychosz KA, Thommes M (2018) Progress in the physisorption characterization of nanoporous gas storage materials. Engineering 4:559-566. https://doi.org/10.1016/j.eng.2018.06.001

36. Thornton AW, Nairn KM, Hill JM, Hill AJ, Hill MR (2009) Metalorganic frameworks impregnated with magnesium-decorated fullerenes for methane and hydrogen storage. J Am Chem Soc 131:10662-10669. https://doi.org/10.1021/ja9036302

37. Paz FAA, Klinowski J, Vilela SMF, Tomé JPC, Cavaleiro JAS, Rocha J (2012) Ligand design for functional metal-organic frameworks. J Chem Soc Rev 41:1088-1110. https://doi.org/10.1039/ C1CS15055C

38. Ma D, Li Y, Li Z (2011) Tuning the moisture stability of metalorganic frameworks by incorporating hydrophobic functional groups at different positions of ligands. Chem Commun 47:73777379. https://doi.org/10.1039/c1cc11752a

39. Getman RB, Bae Y-S, Wilmer CE, Snurr RQ (2012) Review and analysis of molecular simulations of methane, hydrogen, and acetylene storage in metal-organic frameworks. Chem Rev 112:703-723. https://doi.org/10.1021/cr200217c

40. Han SS, Goddard WA (2007) Lithium-doped metal-organic frameworks for reversible $\mathrm{H}_{2}$ storage at ambient temperature. J Am Chem Soc 129:8422-8423. https://doi.org/10.1021/ja072599+

41. Lan J, Cao D, Wang W (2010) High uptakes of methane in Lidoped 3D covalent organic frameworks. Langmuir 26:220-226. https://doi.org/10.1021/la9020383

Publisher's Note Springer Nature remains neutral with regard to jurisdictional claims in published maps and institutional affiliations. 